\title{
Biomarkers to Predict Alcohol Withdrawal Seizures - A Review of Current Literature
}

\author{
Thomas Hillemacher*, Julia Cramer, Annelie Hintzen, Deniz Karagülle and Stefan Bleich \\ Department of Psychiatry, Social Psychiatry and Psychotherapy, Center for Addiction Research, Medical School \\ Hannover, Carl-Neuberg-Str. 1, D-30625 Hannover, Germany
}

\begin{abstract}
Alcohol withdrawal seizures are one major complication during detoxification treatment of alcohol dependent patients. Anticonvulsive pharmaceutical treatment can be administered but is associated with side-effects like nausea or hyponatriemia. Recent studies have identified different biomarkers that have been associated with the risk of alcohol withdrawal seizures. The aminoacid homocysteine as well as prolactin have been described to be associated with this individual seizure risk. Furthermore, markers of alcohol dependence like carbohydrate deficient transferrin (CDT) have been studied in this context. Also, genetic variants like the apolipoprotein E genotype have been found to be related to the history of withdrawal seizures. Knowledge and critical valuation of these recent findings on biomarkers may help to establish an assessment of the individual risk for withdrawal seizures and therefore may have important clinical implications.
\end{abstract}

Keywords: Alcohol withdrawal, seizures, CDT, homocysteine, prolactin, detoxcification, dependence, alcoholism.

\section{INTRODUCTION}

Alcohol withdrawal seizures are a common and severe complication of alcohol detoxification. Therefore, predicting the course of alcohol withdrawal and alcohol withdrawal seizures seems to be useful and tempting. Several recent studies have focused on biological parameters that may help to assess the individual risk for alcohol withdrawal seizures. This may help to establish an individualized pharmacological treatment to prevent alcohol withdrawal seizures in patients of high risk and to avoid unnecessary treatment in other.

Up to now the pathophysiological mechanisms in the genesis of alcohol withdrawal seizures are only partially revealed. Homocysteine, an excitatory amino acid, is evidentially elevated in non-abstinent alcoholics, with a steadily decrease during alcohol withdrawal [1-3]. Recent studies showed the impact of elevated homocysteine serum levels on alcohol withdrawal seizures: for first-onset [4] and for previous withdrawal seizures [5].

Also, elevated prolactin levels have been reported under chronic ethanol exposure [6-8]. Post-ictal prolactin elevation is a well known phenomenon in patients with epilepsia [9] but has also been described after alcohol-related seizures [10]. A recent study now found that patients with a history of alcohol withdrawal seizures show significantly elevated prolactin serum levels at admission (not post-ictal). Therefore, it has been suggested that prolactin may also serve as a (prae-ictal) marker assessing the individual risk for alcohol withdrawal seizures [11].

\footnotetext{
*Address correspondence to this author at the Department of Psychiatry, Social Psychiatry and Psychotherapy, Center for Addiction Research, Medical School Hannover, Carl-Neuberg-Str. 1, D-30625 Hannover, Germany; Tel: +49 511 5326561; Fax: +49 511 5322405;

E-mail: hillemacher.thomas@mh-hannover.de
}

Additionally, a recent investigation focused on the validity of carbohydrate deficient transferring as a diagnostic aid for alcohol withdrawal seizures [12]. Also, genetic variants like the apoE polymorphisms have been associated with elevated risk for alcohol withdrawal seizures in patients undergoing alcohol detoxification [13]. Aim of this review is to give an overview about the existing literature on these biological markers and their potential to predict the individual risk for alcohol withdrawal seizures in patients with alcohol dependence.

\section{THE AMINOACID HOMOCYSTEINE}

Homocysteine is a sulphur-containing amino acid which is produced as a potentially toxic intermediate product in the metabolism of the essential amino acid methionine. Several investigations in recent years described that alcohol consumption, particularly in actively drinking alcoholics, is closely associated with elevated plasma homocysteine levels [1-3]. Also, homocysteine serum levels show a high positive correlation with the blood alcohol concentration. It is important to mention that a single intoxication, also including large amounts of alcohol, does not lead to a pathological elevation of plasma homocysteine concentrations in healthy, not alcohol-dependent subjects [14]. Hence, regular and continuous alcohol consumption seem to be an important and necessary condition, since a significant increase in plasma homocysteine concentrations has been observed in social drinkers with daily consumption of smaller amounts of alcohol [15]. This association between alcohol consumption and raised plasma levels of homocysteine might account for different pathophysiologic consequences such as brain atrophy [16], cognition deficits during alcohol detoxification [17] and withdrawal seizures $[4,18]$. A suggested association with alcohol craving could not be confirmed in a recent investigation [19]. As elevated plasma homocysteine concentrations are also linked to other neuropsychiatric disorders such as depression [20, 21], 
schizophrenia [22] and cognitive impairment [23], an impact of elevated homocysteine levels on frequent comorbidities in alcohol dependent patients can be assumed.

The exact pathophysiological mechanisms of hyperhomocysteinemia causing alcohol withdrawal seizures in patients undergoing alcohol detoxification are still not completely revealed. The most reliable hypothesis is that hyperhomocysteinemia due to chronic alcohol consumption leads to an up-regulation of the NMDA receptor system. However, ethanol acts as a NMDA receptor antagonist, blocking the up-regulation of the NMDA receptor system. Then, during detoxification, excitatory amino acids such as glutamate and homocysteine lead to an overstimulation of NMDA receptors, while the simultaneous removal of the inhibitory effect of ethanol intensifies this stimulation [1, 24]. Course measurements during an alcohol withdrawal treatment showed a continuous reduction in plasma homocysteine levels, which return to normal range after several days of alcohol withdrawal [2, 4, 5, 25].

Additonal evidence regarding the involvement of homocysteine in seizure activity has been brought from experimental studies. It has been shown that systemic infusion of homocysteine is able to generate tonic-clonic seizures in rats [26]. Other studies with NMDA and nonNMDA antagonists showed a protective effect against homocysteine-induced seizures [27, 28]. Conclusively, homocysteine seems to play a central role in a shared biochemical cascade, involving overstimulation of NMDA receptors, oxidative stress, activation of caspases, DNA damage and mitochondrial dysfunction, which are crucial in the pathogenesis of excitotoxicity leading to neuronal cell loss $[24,29,30]$.

Clinically, recent studies brought evidence for an association between homocysteine plasma levels and the risk of alcohol withdrawal seizures. So, homocysteine levels have been shown to predict first-onset alcohol withdrawal seizures in patients with alcoholism $[4,5,18,31]$. In this context, different cut-off levels for homocysteine plasma levels have been proposed in the last years, while most define normal fasting plasma levels of total homocysteine between 5 and $15 \mu \mathrm{mol} / 1$. Moderately elevated homocysteine levels range between 16 and $30 \mu \mathrm{mol} / 1$, intermediately elevated homocysteine levels between 31 and $100 \mu \mathrm{mol} / \mathrm{l}$, and severe hyperhomocysteinaemia is present at over $100 \mu \mathrm{mol} / \mathrm{l}$. Studies have shown that in populations without evidence of a nutritional deficit, a reference interval of between 4.9 and $11.7 \mu \mathrm{mol} / 1$ may be more adequate [32]. However, these cut-off levels are of limited use in the prediction of alcohol withdrawal seizures in alcoholdependent patients, as in this patients group homocysteine levels are usually highly elevated. For clinical guidance, a recent study has calculated predictive cut-off values for alcohol withdrawal seizures risk assessment, using homocysteine plasma levels. This study found the highest combined sensitivity and specificity to suffer from a firstonset alcohol withdrawal seizure at a homocysteine plasma level of $23.9 \mu \mathrm{mol} / \mathrm{l}$, while the authors describe that the negative predictive value $(15.8 \mu \mathrm{mol} / \mathrm{l})$ is probably of higher clinical relevance [31]. In patients above this cut-off value a prophylactic medication with an antiepileptic drug should be taken into account.

\section{CARBOHYDRATE DEFICIENT TRANSFERRING AND OTHER ALCOHOL-RELATED MARKERS}

The validity of carbohydrate deficient transferring (CDT) and other alcohol-related markers to predict alcohol withdrawal seizures was subject of a recent investigation [12]. In this study, CDT at a cut off value of $5.4 \%$ (\%CDT) showed the best predictive validity (sensitivity 39\%, specificity $88 \%$ ). The other markers that were studied in this investigation (s-ethanol, GGT, ASAT and ALAT) showed less predictive values. The authors state that CDT alone can not be recommended as marker to provide useful predictive information regarding the individual seizure risk. Furthermore, in this study concomitant use of anticonvulsive drugs had an important impact on CDT concentrations which questions the described predictive qualities of CDT. Also, the authors discuss the many possible influencing factors on CDT concentration such as iron deficiency, elevated body mass index.

\section{PROLACTIN AS A PREDICTOR OF WITHDRAWAL SEIZURES}

Various studies described an elevation of prolactin serum levels after acute and chronic ethanol exposure [6-8], normalizing during abstinence $[33,34]$. Recent investigations have linked changes of prolactin serum levels with craving for alcohol in specific subgroups of patients, particularly patients of Lesch's type 2 of alcohol dependence and female patients [35, 36].

Elevated prolactin levels have also been discussed to be an important marker in differential diagnosis between pseudoepileptic $v s$ epileptic seizures [9], being elevated after generalized epileptic seizures. While results about the clinical utility of prolactin measurement are contradicting [37-39] prolactin measurement is routinely used for differential diagnosis of seizures in many hospitals. Furthermore, previous studies found that prolactin is also elevated after generalized alcohol withdrawal seizures [10]. Prolactin is supposed to be associated with the dopaminergic system as dopamine inhibits the release of prolactin in the hypothalamus [40]. However, recent studies have linked prolactin with glutamatergic neurotransmission, especially with the NMDA-receptor system [41-44]. Thus, it is feasible that an elevation of prolactin serum levels above the normalrange may be a sign of disturbed glutamatergic neurotransmission. A recent investigation now assessed the possible predictive utility of prolactin serum levels for the individual risk for alcohol withdrawal seizures [11].

Findings of this study suggest that elevated prolactin serum levels could serve as a marker of increased risk of seizures during alcohol withdrawal. The authors suppose that prolactin is not directly involved in the pathophysiology of withdrawal seizures (in contrast to homocysteine) but may be a marker for a disturbance of the glutamatergic and dopaminergic system during alcohol withdrawal [11]. However, this first study showed evidence for an association between elevated prolactin serum levels and the individual risk for alcohol withdrawal seizures. Evidently, before establishing prolactin measurement in clinical practice further studies are necessary including larger samples and different populations. 
Furthermore, a recent study investigated a combined assessment of homocysteine and prolactin [45]. The findings of this investigation show better predicting qualities for homocysteine than for prolactine while the combined assessment of both variables leads to an increase of the predictive value. However, the results also show that the combined assessment seems to be clinically unsatisfactory. The authors discuss this as a consequence of the shared pathophysiological pathway of both parameters.

\section{GENETIC VARIANTS AND THEIR RISK FOR WITHDRAWAL SEIZURES}

Genetic factors regarding the personal risk for alcohol withdrawal seizures have been described in various studies. Schaumann et al. described 1994 in a family-based study a relevant role of genetic predisposition in development of alcohol withdrawal seizures [46].

Recent studies focused on the pathophysiological role of the dopamine transporter gene (DAT gene) as a risk factor for alcohol withdrawal seizures [47]. Particularly, the 3' part of the dopamine transporter gene DAT1/SLC6A3 has recently been associated with an increased risk for alcohol withdrawal seizures [48].

Additionally, the methylenetetrahydrofolate reductase (MTHFR) C6777T polymorphism has received recent attention. This polymorphism is of high importance in the homocysteine metabolism [49]. In this study, Lutz et al. described results of 221 alcoholic patients. They found that the T-allele is associated with a history of alcohol withdrawal seizures, compared to patients with only mild withdrawal syndrome and healthy controls. The authors conclude that the MTHFR polymorphism may have an influence in the pathogenesis of alcohol withdrawal seizures [49].

Besides this, recent research has been attracting increasing attention concerning the pathophysiological role of the apolipoprotein $\mathrm{E}$ gene (ApoE gene) and its alleles (ApoE2, ApoE3, ApoE4) in different psychiatric and neurological disorders. The results of various studies show that the apolipoprotein E4 allele has to be regarded as a vulnerability factor for a higher incidence of neurodegenerative diseases as well as for a reduced capacity for neuronal regeneration. Recently, a significant relationship between the ApoE4 allele and hippocampal atrophy in females with alcoholism has been observed [50].

Regarding epileptic seizures, it has been observed that ApoE polymorphism is not associated with the development of major seizure disorders including temporal lobe epilepsy [51-53]. Nevertheless, studies reported an earlier onset of chronic temporal lobe epilepsy [54] as well as increased risk of late posttraumatic seizures [55] in patients carrying the ApoE4 genotype.

A recent study now focused on a possible association between apolipoprotein E polymorphism and the individual risk of alcohol withdrawal seizures in patients suffering from alcohol dependence [13]. Surprisingly, in this study it was not the ApoE4 gene variant which was associated with alcohol withdrawal seizures. Instead, the authors found a significant association with the ApoE3 allele. According to these results patients carrying the ApoE2 allele were unlikely to report a history of withdrawal seizures during the course of their disease. The authors state that these preliminary findings have to be interpreted carefully but they hint towards the possibility that in patients with diagnosis of alcohol dependence the ApoE2 genotype might have a protective effect concerning the risk of developing alcohol withdrawal seizures. A protective effect of the E2 allele has also been reported in other neurological disorders such as ischemic cerebrovascular diseases and vascular dementia [56], age at onset of amyotrophic lateral sclerosis [57] and episodic memory decline in older persons [58].

\section{CONCLUSION AND CLINICAL IMPLICATION}

Clinically, a serological assessment of the individual risk for alcohol withdrawal seizures is of high importance. In many patients it is difficult to estimate this risk by the often insufficient medical history given at admission as many patients are admitted acutely intoxicated or with severe

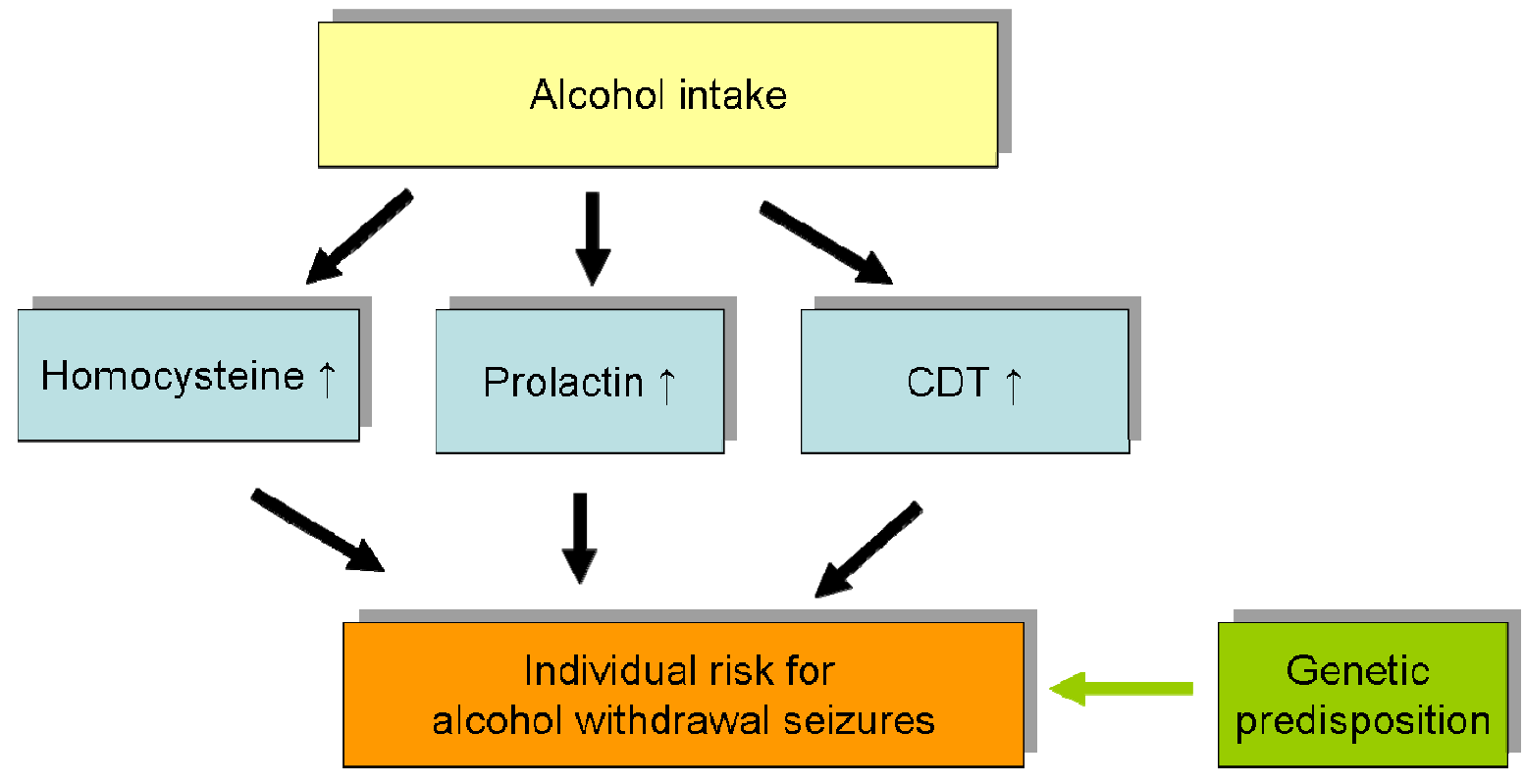

Fig. (1). Model of biomarkers to predict alcohol withdrawal seizures. 
alcohol withdrawal syndrome. Recent investigations focused on different genetic and serological markers which in the future may help to establish a blood-based individual risk assessment. Such a risk assessment could lead to a personalized pharmacological treatment of alcohol withdrawal. The amino acid homocysteine seems to be of special interest in this context but its predictive values may be enhanced by other parameters like CDT, prolactin or an assessment of different genetic factors (Fig. 1). However, there is still insufficient evidence to establish such a risk assessment for clinical use. At this time, best evidence has been shown for homocysteine with the described negative predictive value of $15.8 \mu \mathrm{mol} / 1$ for decision regarding anticonvulsive therapy [31]. The present overview is limited by the absence of profound clinical studies in large populations to assess clinical evidence for the stated biomarkers. Another limitation is that most of the present findings are correlation in nature and lack evident pathophysiological models explaining a casual connection between biomarkers and alcohol withdrawal seizures. Therefore, further research is necessary and should 1) focus on the casual connections between these biomarkers and the genesis of alcohol withdrawal seizures in human and animal studies, 2) further investigate the clinical use of singular or combined assessment of these biomarkers and 3) evaluate, how these biomarkers fit with standard clinical assessment of risk including questionnaires like AUDIT [59].

\section{REFERENCES}

[1] Bleich S, Degner D, Javaheripour K, Kurth C, Kornhuber J. Homocysteine and alcoholism. J Neural Transm Suppl 2000: 18796.

[2] Bleich S, Degner D, Wiltfang J, et al. Elevated homocysteine levels in alcohol withdrawal. Alcohol Alcohol 2000; 35: 351-54.

[3] Bleich S, Carl M, Bayerlein K, et al. Evidence of increased homocysteine levels in alcoholism: the Franconian alcoholism research studies (FARS). Alcohol Clin Exp Res 2005; 29: 334-6.

[4] Bleich S, Degner D, Bandelow B, et al. Plasma homocysteine is a predictor of alcohol withdrawal seizures. Neuroreport 2000; 11: 2749-52.

[5] Bayerlein K, Hillemacher T, Reulbach U, et al. Alcoholismassociated hyperhomocysteinemia and previous withdrawal seizures. Biol Psychiatry 2005; 57: 1590-3.

[6] De A, Boyadjieva N, Oomizu S, Sarkar DK. Ethanol induces hyperprolactinemia by increasing prolactin release and lactotrope growth in female rats. Alcohol Clin Exp Res 2002; 26: 1420-9.

[7] Emanuele NV, Lapaglia N, Emanuele MA. Impact of acute and chronic ethanol exposure on prolactin in both male and female rats. Endocrine 2001; 16: 29-37.

[8] Schuckit MA, Parker DC, Rossman LR. Ethanol-related prolactin responses and risk for alcoholism. Biol Psychiatry 1983; 18: 11539.

[9] Anzola GP. Predictivity of plasma prolactin levels in differentiating epilepsy from pseudoseizures: a prospective study. Epilepsia 1993; 34: 1044-8.

[10] Mautner VF, Schneider E, Hanisch L. Differential diagnostic value of postictal serum prolactin determination. Nervenarzt 1987; 58: 456-8.

[11] Hillemacher T, Bayerlein K, Frieling H, et al. Elevated prolactin serum levels and history of alcohol withdrawal seizures. J Psychiatr Res 2007; 41: 702-6.

[12] Brathen G, Bjerve KS, Brodtkorb E, Bovim G. Validity of carbohydrate deficient transferrin and other markers as diagnostic aids in the detection of alcohol related seizures. J Neurol Neurosurg Psychiatry 2000; 68: 342-8.

[13] Wilhelm J, von Ahsen N, Hillemacher T, et al. Apolipoprotein E gene polymorphism and previous alcohol withdrawal seizures. J Psychiatr Res 2007; 41: 871-5.

[14] Bleich S, Degner D, Kropp S, Ruther E, Kornhuber J. Red wine, spirits, beer and serum homocysteine. Lancet 2000; 356: 512.
[15] Bleich S, Bleich K, Kropp S, et al. Moderate alcohol consumption in social drinkers raises plasma homocysteine levels: a contradiction to the 'French Paradox'? Alcohol Alcohol 2001; 36: 189-92.

[16] Bleich S, Bandelow B, Javaheripour K, et al. Hyperhomocysteinemia as a new risk factor for brain shrinkage in patients with alcoholism. Neurosci Lett 2003; 335: 179-82.

[17] Wilhelm J, Bayerlein K, Hillemacher T, et al. Short-term cognition deficits during early alcohol withdrawal are associated with elevated plasma homocysteine levels in patients with alcoholism. J Neural Transm 2006; 113: 357-63.

[18] Kurth C, Wegerer V, Degner D, et al. Risk assessment of alcohol withdrawal seizures with a Kohonen feature map. Neuroreport 2001; 12: 1235-8.

[19] Hillemacher $\mathrm{T}$, Reulbach U, Bayerlein $\mathrm{K}$, et al. Plasma homocysteine concentrations do not influence craving in alcohol withdrawal. Alcohol 2004; 34: 211-5.

[20] Bjelland I, Tell GS, Vollset SE, Refsum H, Ueland PM. Folate, vitamin B12, homocysteine, and the MTHFR $677 \mathrm{C}->\mathrm{T}$ polymorphism in anxiety and depression: the Hordaland Homocysteine Study. Arch Gen Psychiatry 2003; 60: 618-26.

[21] Folstein M, Liu T, Peter I, et al. The homocysteine hypothesis of depression. Am J Psychiatry 2007; 164: 861-7.

[22] Brown AS, Bottiglieri T, Schaefer CA, et al. Elevated prenatal homocysteine levels as a risk factor for schizophrenia. Arch Gen Psychiatry 2007; 64: 31-9.

[23] Prins ND, Den Heijer T, Hofman A, et al. Homocysteine and cognitive function in the elderly: the Rotterdam Scan Study. Neurology 2002; 59: 1375-80.

[24] Bleich S, Degner D, Sperling W, et al. Homocysteine as a neurotoxin in chronic alcoholism. Prog Neuropsychopharmacol Biol Psychiatry 2004; 28: 453-64.

[25] Hultberg B, Berglund M, Andersson A, Frank A. Elevated plasma homocysteine in alcoholics. Alcohol Clin Exp Res 1993; 17: 687-9.

[26] Kubova H, Folbergrova J, Mares P. Seizures induced by homocysteine in rats during ontogenesis. Epilepsia 1995; 36: 7506.

[27] Folbergrova J. Anticonvulsant action of both NMDA and nonNMDA receptor antagonists against seizures induced by homocysteine in immature rats. Exp Neurol 1997; 145: 442-50.

[28] Folbergrova J, Haugvicova R, Mares P. Behavioral and metabolic changes in immature rats during seizures induced by homocysteic acid: the protective effect of NMDA and non-NMDA receptor antagonists. Exp Neurol 2000; 161: 336-45.

[29] Lipton SA, Kim WK, Choi YB, et al. Neurotoxicity associated with dual actions of homocysteine at the N-methyl-D-aspartate receptor. Proc Natl Acad Sci USA 1997; 94: 5923-8.

[30] Maler JM, Seifert W, Huther G, et al. Homocysteine induces cell death of rat astrocytes in vitro. Neurosci Lett 2003; 347: 85-8.

[31] Bleich S, Bayerlein K, Hillemacher T, et al. An assessment of the potential value of elevated homocysteine in predicting alcoholwithdrawal seizures. Epilepsia 2006; 47: 934-8.

[32] Ubbink JB, Becker PJ, Vermaak WJ, Delport R. Results of Bvitamin supplementation study used in a prediction model to define a reference range for plasma homocysteine. Clin Chem 1995; 41: 1033-7.

[33] Kutscher S, Heise DJ, Banger M, et al. Concomitant endocrine and immune alterations during alcohol intoxication and acute withdrawal in alcohol-dependent subjects. Neuropsychobiology 2002; 45: 144-9.

[34] Frias J, Rodriguez R, Torres JM, Ruiz E, Ortega E. Effects of acute alcohol intoxication on pituitary-gonadal axis hormones, pituitaryadrenal axis hormones, beta-endorphin and prolactin in human adolescents of both sexes. Life Sci 2000; 67: 1081-6.

[35] Hillemacher T, Bayerlein K, Wilhelm J, et al. Prolactin serum levels and alcohol craving - an analysis using Lesch's typology. Neuropsychobiology 2006; 53: 133-6.

[36] Hillemacher $\mathrm{T}$, Bayerlein $\mathrm{K}$, Wilhelm $\mathrm{J}$, et al. Alteration of prolactin serum levels during alcohol withdrawal correlates with craving in female patients. Addict Biol 2005; 10: 337-43.

[37] Vukmir RB. Does serum prolactin indicate the presence of seizure in the emergency department patient? J Neurol 2004; 251: 736-9.

[38] Shukla G, Bhatia M, Vivekanandhan S, et al. Serum prolactin levels for differentiation [of nonepileptic $v s$ true seizures: limited utility. Epilepsy Behav 2004; 5: 517-21. 
[39] Lusic I, Pintaric I, Hozo I, Boic L, Capkun V. Serum prolactin levels after seizure and syncopal attacks. Seizure 1999; 8: 218-22.

[40] Ben-Jonathan N, Hnasko R. Dopamine as a prolactin (PRL) inhibitor. Endocr Rev 2001; 22: 724-63.

[41] Bregonzio C, Moreno GN, Cabrera RJ, Donoso AO. NMDA receptors in the medial zona incerta stimulate luteinizing hormone and prolactin release. Cell Mol Neurobiol 2004; 24: 331-42.

[42] Bregonzio C, Navarro CE, Donoso AO. NMDA receptor antagonists block stress-induced prolactin release in female rats at estrus. Eur J Pharmacol 1998; 350: 259-65.

[43] Pinilla L, Gonzalez D, Tena-Sempere M, Aguilar R, Aguilar E. Effects of N-methyl-D-aspartate and kainic acid on prolactin secretion in prepubertal female rats. Eur J Endocrinol 1996; 135: 464-8.

[44] Bleich S, Kornhuber J. Glutamate and schizophrenia and the Nmethyl-D-aspartate receptor hypofunction hypothesis. In: Schmidt WJ, Reith MEA, Eds. Dopamine and glutamate in psychiatric disorders. Totowa, New Jersey: Humana Press 2005; pp. 169-79.

[45] Hillemacher T, Frieling H, Bayerlein K, et al. Biological markers to predict previous alcohol withdrawal seizures: a risk assessment. J Neural Transm 2007; 114: 151-4.

[46] Schaumann BA, Annegers JF, Johnson SB, et al. Family history of seizures in posttraumatic and alcohol-associated seizure disorders. Epilepsia 1994; 35: 48-52.

[47] Gorwood P, Limosin F, Batel P, et al. The A9 allele of the dopamine transporter gene is associated with delirium tremens and alcohol-withdrawal seizure. Biol Psychiatry 2003; 53: 85-92.

[48] Le Strat Y, Ramoz N, Pickering P, et al. The 3' part of the dopamine transporter gene DAT1/SLC6A3 is associated with withdrawal seizures in patients with alcohol dependence. Alcohol Clin Exp Res 2008; 32: 27-35.
[49] Lutz UC, Batra A, Kolb W, et al. Methylenetetrahydrofolate reductase C677T-polymorphism and its association with alcohol withdrawal seizure. Alcohol Clin Exp Res 2006; 30: 1966-71.

[50] Bleich S, Wilhelm J, Graesel E, et al. Apolipoprotein E epsilon 4 is associated with hippocampal volume reduction in females with alcoholism. J Neural Transm 2003; 110: 401-11.

[51] Gambardella A, Aguglia U, Cittadella R, et al. Apolipoprotein E polymorphisms and the risk of nonlesional temporal lobe epilepsy. Epilepsia 1999; 40: 1804-07.

[52] Kilpatrick ES, Jagger CE, Spooner RJ, Brodie MJ. Apolipoprotein E and epilepsy. Ann Clin Biochem 1996; 33 ( Pt 2): 146-7.

[53] Yeni SN, Ozkara C, Buyru N, et al. Association between APOE polymorphisms and mesial temporal lobe epilepsy with hippocampal sclerosis. Eur J Neurol 2005; 12: 103-7.

[54] Briellmann RS, Torn-Broers Y, Busuttil BE, et al. APOE epsilon4 genotype is associated with an earlier onset of chronic temporal lobe epilepsy. Neurology 2000; 55: 435-7.

[55] Diaz-Arrastia R, Gong Y, Fair S, et al. Increased risk of late posttraumatic seizures associated with inheritance of APOE epsilon4 allele. Arch Neurol 2003; 60: 818-2.

[56] Lin HF, Lai CL, Tai CT, Lin RT, Liu CK. Apolipoprotein E polymorphism in ischemic cerebrovascular diseases and vascular dementia patients in Taiwan. Neuroepidemiology 2004; 23: 12934.

[57] Li YJ, Pericak-Vance MA, Haines JL, et al. Apolipoprotein E is associated with age at onset of amyotrophic lateral sclerosis. Neurogenetics 2004; 5: 209-13.

[58] Wilson RS, Bienias JL, Berry-Kravis E, Evans DA, Bennett DA. The apolipoprotein E epsilon 2 allele and decline in episodic memory. J Neurol Neurosurg Psychiatry 2002; 73: 672-7.

[59] Brathen G, Ben-Menachem E, Brodtkorb E, et al. EFNS guideline on the diagnosis and management of alcohol-related seizures: report of an EFNS task force. Eur J Neurol 2005; 12: 575-81. 